\title{
A Change is (not) Gonna Come: \\ A twenty-year overview of Italian grandparent-grandchild exchanges
}

\author{
Marta Pasqualini ${ }^{1,3}$, Giorgio Di Gessa ${ }^{2}$, Cecilia Tomassini ${ }^{3}$ \\ ${ }^{1}$ Observatoire sociologique du changement (OSC) Sciences Po, Paris \& University of Molise; \\ email: marta.pasqualini@sciencespo.fr \\ ${ }^{2}$ University College London; email: g.di-gessa@ucl.ac.uk \\ ${ }^{3}$ Università del Molise; email: cecilia.tomassini@unimol.it
}

\begin{abstract}
Levels of coresidence, residential proximity, face-to-face contacts and intergenerational support exchanges remain overall high and stable across European countries. However, to date, few studies have focused on trends in grandparent-grandchild relations. Therefore, this study aims to investigate whether and to what extent grandparent-grandchild exchanges have changed over time. We used data from the Italian Family and Social Subjects (FSS) Surveys, covering the years 1998-2016, and considered three different currencies of exchanges between grandparents and their grandchildren (coresidence, face-to-face contacts, and grandchild care provision). Our results showed stability over time in coresidence, a small reduction in daily contacts (from $47 \%$ in 1998 to $39 \%$ in 2016) and an increase in grandchildren care (from $78 \%$ in 1998 to $82 \%$ in 2016). Also, we found little changes in the associations between such indicators of intergenerational exchanges and the demographic and socio-economic determinants usually used to explain them. Despite changes among Italian grandparents such as increases in their age profile, in education, and in marital disruption, the relations between grandparents and their grandchildren have so far remained stable over time, with generally high levels of intergenerational exchanges.
\end{abstract}

Keywords: grandparents; grandchildren; intergenerational exchanges; trends; grandparenting; grandchild care provision; face-to-face contacts; coresidence; family; ageing; Italy 


\section{Introduction}

Although several studies have hypothesised that industrialisation and urbanisation would lead to a convergence of family life towards the nuclear family and a decline in intergenerational exchanges (Popenoe 1993), evidence at the beginning of the $21^{\text {st }}$ century suggests that levels of solidarity between family members across generations remain overall high and stable (Kalmijn and De Vries 2009), although trends depend also on the dimensions of intergenerational solidarity that underlie and shape the relations and exchanges between the generations (Grundy 2000; Grundy and Shelton 2001; Mazurik et al. 2020; Pilkauskas and Cross 2018; Ruggles 2007; Steinbach et al. 2019; Treas and Gubernskaya 2012; van der Pas et al. 2007).

To date, however, most of the research on trends in intergenerational family exchanges has focused on parent-child relationships, excluding family relations across more than two adult generations and grandparent-grandchild relationships in particular. Increased life expectancy means that it is now quite common for children to grow up while their grandparents and even great grandparents are still living (Murphy 2011; Post et al. 1997). Moreover, it is often assumed that in response to sociodemographic changes, such as more mothers in the labour market and higher levels of divorce and separation, grandparents are increasingly more likely to play an important role as providers of financial, emotional, and practical support (Herlofson and Hagestad 2012), especially in countries where public services are limited (Di Gessa et al. 2016; Zamberletti et al. 2018).

Few studies have investigated trends in grandparent-grandchild relationships. Research on intergenerational households shows complex trends, with declines in three-generation households between 1981 and 2001 in Austria, France, Greece, and Portugal but increases in Romania and the US as well as in England and Wales in the first decades of the $21^{\text {st }}$ century (Glaser et al. 2018, Albuquerque 2011). To our knowledge, Geurts and colleagues (2015) were the only authors who investigated changes in grandchild care. whereas no research has focused on trends and changes in contacts between grandparents and grandchildren.

Thus, our paper aims to describe trends in grandparents-grandchildren exchanges in Italy. We use data from four waves of the Italian Family and Social Subjects (FSS) Surveys which cover a period of nearly 20 years (from 1998 to 2016) and consider three measures of intergenerational exchanges, that is coresidence, face-to-face contacts, and childcare provision. Our study also examines the socioeconomic and demographic characteristics associated with each measure of intergenerational exchanges over time; and whether these associations have changed over time. 


\section{Background}

Cross-country and over-time changes in intergenerational parent-child relationships are related to several structural socio-demographic and health factors that may play a major role in shaping such exchanges (Tomassini et al. 2004a, Hank 2007, Albertini \& Kohli 2013). Grandparent-grandchild exchanges are embedded within multigenerational family systems and are therefore contingent upon grandparent-parent relationships (Mueller and Elder 2004); it can be hypothesised that factors affecting parent-child relationships might 'spill over' to influence also grandparent-grandchild relationships. For instance, divorce of grandparents (G1) or their children/children-in-law (G2) may reduce G1-G2 relationship quality, mutual support, and contacts perhaps due to greater geographic mobility, social disapproval from family or friends, or loss of reciprocal obligations (Cherlin and Furstenberg 1992; Ganong and Coleman, 2006). This, in turn, could negatively affect G1's level of involvement and contact with their grandchildren (G3) (Albertini and Tosi 2018, Oppelaar and Dykstra 2004, Taylor et al. 2005). Other pivotal demographic and social transformations -such as the increase in the level of education and labour force participation of older generations, and women in particular -are also thought to be associated in complex ways with G1-G3 exchanges, for both structural and cultural reasons (Kalmijn 2006). For example, as highly educated people are hypothesised to be more individualistic (Thornton and Young-DeMarco, 2001) and are more likely to live farther away from their family members (Silverstein, 1995), one can expect highly educated grandparents to have fewer contacts with their grandchildren and to be less likely to provide intensive grandchild care as they prefer to be 'busy with' social and leisure activities (McGarrigle et al. 2018). Changes in the labour market participations often assume that grandparents would increase their engagement in grandchild provision as more mothers are employed (Geurts et al. 2015). However, as more grandparents and grandmothers in particular are also encouraged to participate in the labour market, G1-G3 exchanges (and childcare provision in particular) may decline as workers tend to have less time for caring responsibilities (Hank and Buber 2009; Di Gessa et al. 2016a; Igel and Szydlik, 2011). Health status has an ambiguous association with intergenerational exchanges: older people tend to interact with younger generations either when they need support because health problems occur, or when they are fit and healthy enough to care for them (Tomassini et al.2004b). Specific studies on grandparents have found that health is an important factor affecting their ability to look after grandchildren (Di Gessa et al. 2016b; Glaser et al. 2013) as well the frequency of contact with grandchilren (Oppelar and Dykstra 2004). Additionally, demographic trends in fertility may shape variations in intergenerational exchanges between generations over time (Tomassini et al. 2004a, Grundy and Read 2012). Increases in the age at motherhood (and in the age at grandparenthood) could reduce grandparent-grandchild exchanges, as older grandparents are generally less likely to provide 
care for their grandchildren (Zamberletti et al. 2018) and to have contacts with them (Uhlenberg and Hamill 1998). Declines in family size and in number of grandchildren could affect G3-G1 relationships in different ways. For example, when analysing childcare provision, grandparent with a large number of grandchildren may find it difficult to provide regular and intensive hours of care to each of them (Zamberletti et al. 2018, Uhlenberg and Hamill 1998). It is possible that, when it comes to face-to-face contacts, one could postulate that grandparents with fewer grandchildren would have less contact with them due to the shrinking of the potential pool available to them (Aassve et al. 2012). Finally, mobility of younger generations and patterns of migration among adult and younger children in particular may weaken G3-G1 relationships and face-to-face exchanges, even though, to date, evidence suggests that the proportion of older parents with at least one child (and therefore a potential grandchild) in close proximity remains high (Wolf and Longino, 2005; Tomassini and Lamura, 2009).

Given the socio-demographic changes that occurred in recent decades in European countries, with increasing educational attainments, general upward trends in divorce rates, increasing labour force participation of women and of those in later life, as well as an overall postponment of the age of birth of the first child and a reduction in family sizes, it is reasonable to believe that grandparent-grandchild relationships might have changed over time. However, to date, very few studies have analysed changes in this relationship, partly because questions about grandparents' exchanges with their grandchildren (including coresidence, grandchild care, and contact) have been only recently introduced in large quantitative surveys and not always with comparable questions over time (Hank et al. 2018). A cross-country comparison on trends in coresidence between grandparents and grandchildren by Glaser and colleagues (2018) showed relatively stable and low prevalence of threegeneration households in the European countries they considered between 1970 and 2002, with the exception of the US and Romania with increasing incidence. To our knowledge, Guerts and collegues' work (2015) is the only study that investigated changes in the provision of grandparental care over time. Using data from the Longitudinal Aging Study Amsterdam and focusing on grandparents aged 58-68 in 1992 and in 2006, the authors found that the probability of grandparental care increased from $23 \%$ in 1992 to $41 \%$ in 2006, and that this increase in grandchild care provision was mostly attributable to higher rates of mothers' participation to the labour force, the higher incidence of single motherhood, as well as having fewer grandchildren (and 'less competion among them'). However, Guerts et al. (2015) also found that increases in grandparents' own employment reduced grandchild care provision.

Overall, the knowledge of changes over time in the relationships between grandparents and grandchildren remains limited, with no studies so far that have investigated face-to-face contacts. This paper, therefore, contributes to this gap by investigating changes in grandparent-grandchild 
relationships over almost 2 decades in Italy. We consider three types of exchanges (namely coresidence, contact and grandparental childcare) in a country, Italy, known for its modest availability of formal support for children (Saraceno 2020; Bordone et al. 2016), and for its recent dramatic societal and demographic shifts, including reduced and delayed fertility, postponements of age at grandparenthood (Di Gessa et al., 2020a) and increased female labour market participation (Mancini, 2017). Understanding trends in grandparent-grandchild exchanges and the stability/change in the effects of the factors associated with them may prove particularly useful in a country where grandparents play an important role in society and family life. In Italy, about $43 \%$ of grandchildren aged 0-13 are cared for by grandparents aged 50 and older occasionally and about 30\% are looked after by them almost daily when their parents are at work (Zamberletti et al. 2018). The availability of such informal childcare is key to the Italian maternal labour force participation, particularly among the most socio-economically disadvantaged mothers (Arpino et al. 2014).

This paper, therefore, aims to describe changes in grandparent-grandchild relationships (measured in terms of coresidence, contact, and care) in Italy, and specifically to answer the following research questions:

- RQ1. Have grandparent-grandchild exchanges changed across time in Italy?

- RQ2. To what extent are potential changes in intergenerational exchanges over time due to (a) population compositional factors (such as education, employment, living arrangements, etc.) and/or to (b) the changes of the association between them over time?

\section{Data and Methods}

\section{Study Population}

Data is drawn from the Family and Social Subjects (FSS) surveys carried out by the Italian Institute of Statistics (ISTAT) in 1998, 2003, 2009 and 2016 (the latter released in mid 2020). These are independent nationally-representative cross-sectional studies based on Italian private households selected from the Register of Population, which collect information on a range of demographic and socio-economic characteristics ${ }^{1}$. The response rate for each survey ranges between $75 \%$ and $80 \%$ (ISTAT, 2016).

\footnotetext{
${ }^{1}$ The last survey, collected in 2016, differs from the previous ones as it does not cover information of all the household members but only of the main respondents. However, the distribution of the main individual characteristic does not differ across surveys.
} 
The analytic sample is restricted to respondents aged $35+$ who are grandparents ${ }^{2}$ and it consists of 9578 individuals in 1998 (that is, 30.26\% out of the 31,648 individuals aged 35+), 10315 in 2003 (34.24\%), 9659 in 2009 (34.48\%) and 6255 in 2016 (31.80\%). As detailed in the results section below, samples for all surveys were smaller when we considered the provision of care to grandchildren as questions related to this topic were collected only about up to three non-coresidential grandchildren aged 13 or younger.

\section{Outcome variables}

We consider three measures of grandparent-grandchild exchanges: co-residence with at least one grandchild, face-to-face contacts, and frequency of provision of grandchild care. Grandparents are classified as co-residing with a grandchild if they report that at least one of their grandchildren live with them in the same household. Grandparents are also asked about the frequency of face-to-face contact with up to three non-coresidential grandchildren (once a day, more than once a week, once a week, less than four times a month, few times a year and never). We distinguish between grandparents who have daily face-to-face contacts ${ }^{3}$ with at least one of the grandchildren versus those who have less frequent contacts. In all surveys, grandparents with at least one grandchild below the age of $13^{4}$ are asked for up to three grandchildren whether and during which occasions they look after them (i.e. Never; When their parents work; During occasional commitments of parents; When parents want to go out in their free time; During the holiday periods; When the grandchild is sick; In times of emergency; Other). Using this information, we distinguish four types of hierarchical mutually exclusive grandparental childcare: intensive (i.e. those who look after at least one grandchild when parents are at work); holidays caregivers (i.e. those who provide grandchild care during the holidays -which last about 12/13 consecutive weeks in the summer- but not when parents are at work), occasional (i.e. grandparents who mostly reported grandchild care on a non-regular basis to help parents on specific occasions but not during holidays and when parents are at work) and those grandparents who never care their grandchildren.

\section{Independent Variables}

In line with extensive literature investigating individual characteristics associated with coresidence, grandparent-grandchild contacts, and grandparental childcare, we consider several grandparents'

\footnotetext{
${ }^{2}$ In all surveys, only respondents aged $35+$ are asked if they are grandparents. For consistency, we used the agethreshold identified by ISTAT in all our analyses.

${ }^{3}$ We use this threshold as more than $40 \%$ of grandparents report daily contacts with their grandchildren in each survey. Additional analyses (available upon request) carried out using a dichotomous variable which distinguished between 'at least weekly' vs 'less frequent' contact showed similar findings. Respondents having coresident grandchildren only were excluded from this analysis.

${ }^{4}$ Descriptive statistics on this subsample are listed in Table S.1 of the Appendix.
} 
characteristics in our study (Bordone et al. 2016; Di Gessa et al. 2016; Di Gessa et al. 2020b; FullerThomson and Minkler 2001; Hank and Buber 2009; Herlofson and Hagestad 2012; Igel and Szyklik 2011). As indicators of socio-demographic characteristics we control for grandparent's gender, their age $(<49 ; \quad 50-59 ; \quad 60-74 ; \quad 75+)^{5}$, marital status (Married/cohabiting; Widowed; Separated/Divorced/Never married) and macro-region of residence (North; Centre; or South of Italy). As indicators of grandparents' socio-economic circumstances, we include educational attainment (High school diploma or above vs lower educational attainments) and working status (In paid work; Retired; Other) at the time of the interview. None of the surveys collect information on wealth. Therefore, as indicators of financial wellbeing, we include a dichotomous variable indicating whether grandparents receive an income or not. Also, as an indicator of health, we control for the presence of chronic diseases as this is the only measure of health comparable across the four surveys. In particular, for the first two waves (1998 and 2003) grandparents are asked whether they suffer from a chronic illness or a permanent disability that reduces personal autonomy and requires the help of other people. In the 2009 and 2016 surveys, however, respondents have to report whether they have severe, non-severe, or no limitations to daily life activities. We created a single variable distinguishing grandparents without any limiting diseases from those who had limiting long-standing illness or disability. Finally, we also include grandchild's characteristics, as family structures have been associated with grandparent-grandchild relationships and childcare provision (Di Gessa et al., 2016; Herlofson and Hagestad, 2012; Igel and Szyklik, 2011, Zamberletti et al., 2018). In particular, we includ the total number of grandchildren grandparents have, as grandparents with more grandchildren may limit the amount of support and interactions they can provide to a specific one. We also control for geographical distance to the nearest grandchild (at least one grandchild living $<1 \mathrm{Km}$ including co-residence; the closest grandchild living between 1 and $16 \mathrm{Km}$; all of them living $16 \mathrm{Km}$ or more $)^{6}$. To avoid any issue related to a possible overlap between co-residence and proximity effects, this variable has been included only in the last two models on daily face-to-face contacts and childcare.

\section{Statistical Model}

Firstly, to investigate the associations between grandparents' characteristics and exchanges over time, we employ logistic and multinomial logistic regression models both by pooling waves and using a timing variable as a covariate, and by separating the analyses by wave (1998, 2003, 2009, 2016). In particular, logistic models are used to study co-residence with at least one grandchild (Model 1) and daily contacts with grandchildren (Model 2); while multinomial models are used for grandchild care

\footnotetext{
${ }^{5}$ Due to a privacy issue, ISTAT releases only a 10 years categorical variable.

${ }^{6}$ Living proximity has not been included in the model exploring the likelihood of co-residing with at least one grandchild.
} 
(Model 3). Secondly, to test whether the estimated associations change over time (null hypothesis $\mathrm{H}_{0}: \beta_{1998} \beta_{2016}$ ), a pooled sample multivariate model is estimated interacting the survey timing with each covariate (available upon request). The test statistic for the interaction coefficient between each covariate described above and the survey timing variable (1998 as reference category) is reported in all tables. To ease the interpretation, we compute the Average Marginal Effects (AMEs) which express how the probability of observing the outcome changes when a specific independent variable changes. All the analyses are performed using Stata 15.1.

\section{Results}

\section{RQ1. Have grandparent-grandchild exchanges changed across time in Italy?}

Table 1 (top part) lists the weighted distribution of the main indicators of grandparent-grandchild exchanges over time, which allow us to answer the first research question (RQ1). From a descriptive perspective, the prevalence of grandparents living with at least one grandchild broadly remained stable across time at about $7 \%$. The prevalence of grandparents reporting daily face-to-face contact with grandchildren decreased by almost 8 percentage points from $47.7 \%$ in 1998 to $39.4 \%$ in 2016 . The distribution of grandchild care provision changed over time with an increase of about 10 percentage points in the number of grandparents providing intensive care between 1998 and 2016. A slightly decrease has been observed among those who looked after grandchildren occasionally (39\% in 1998 vs $34 \%$ in 2016). The percentage of grandparents who cared during the holidays remain constant during the considered period. Finally, the percentage of grandparents who never looked after grandchildren decreased from about $21 \%$ to $17 \%$ in the latest wave.

These trends in grandparent-grandchild exchanges show a general stability over the last twenty years in intergenerational coresidence, a slightly increase of those reporting to care grandchild(ren) and a slight reduction in face-to-face contacts. These trends were also confirmed by pooled regression analyses using survey timing as covariate (available upon request).

[Table 1 about here]

RQ2a. To what extent are potential changes in intergenerational exchanges over time due to population compositional factors?

Table 1 (bottom part) shows weighted descriptive statistics of grandparents' demographic and socioeconomic characteristics over time (RQ2a). Gender, marital status, paid employment and income remained broadly stable over time. Women represented $60 \%$ of grandparents in each survey considered; there was an increase in the percentage of divorced/separated/never married grandparents (from 3\% in 1998 to almost $8 \%$ in 2016) although two thirds of grandparents were married 
throughout; only one in ten grandparents were in paid work; finally, about $85 \%$ of them had their own income. The geographical macro area of residence did not change significantly, with about $45 \%$ of grandparents residing in the North of Italy as for the general population. However, grandparents' age profile, their education, and the average number of grandchildren changed dramatically over time. For instance, whereas in 1998 24\% of grandparents were younger than 60 and 27\% were aged 75 and older, about 20 years later the percentages were 14 and 38 respectively. Moreover, the percentage of respondents with at least a high-school degree rose from $9 \%$ in 1998 to 22\% in 2016. Also, in less than 20 years, the average number of grandchildren decreased from 3.48 in 1998 to 2.97 in 2016. Finally, the distance to their closest grandchild increased slightly over time with $12 \%$ of grandparents having their closest grandchild more than $16 \mathrm{Km}$ away in 1998 compared to $17 \%$ in 2016. Changes of compositional factors over time have been additionally confirmed by statistical tests (see Table 5 for a summary of main findings).

RQ2b. To what extent are potential changes in intergenerational exchanges over time due the changes of the association between them over time?

\section{Coresidence with grandchild(ren)}

Tables 2 to 4 show predicted probabilities related to grandparent-grandchild exchanges indicators (RQ2b). Table 2 shows AMEs from the logistic regression model for coresidence with at least one grandchild. Overall, compared to grandparents age 50-59, those aged 49 and younger were more likely to live with at least one grandchild at each wave. Conversely, grandparents aged 75+ were significantly more likely to live with at least one grandchild in 1998 (AMEs $=0.032, \mathrm{p}<0.001$ ) and 2003 (AMEs $=0.022, \mathrm{p}<0.01$, while they were less likely to do so in 2009 (AMEs $=-0.023 ; \mathrm{p}>0.1$ ) and in 2016 (AMEs $=-0.062 ; \mathrm{p}<0.01)$. Results also suggest changes in the associations between marital status and coresidence with grandchildren. Whereas widowed grandparents were significantly more likely than married ones to live with grandchild(ren) across all time points, the magnitude of this association decreased over time (i.e., AMEs $1998=0.121, \mathrm{p}<0.001$; AMEs $2016=0.046$, $\mathrm{p}<0.001)$. Similarly, divorced/separated/never married grandparents were significantly more likely to coreside with grandchild(ren) in 1998 (AMEs =0.047, p<0.05), 2003 (AMEs =0.028, p<0.05), and 2009 (AMEs $=0.039, \mathrm{p}<0.01)$ but not in 2016 (AMEs $=-0.006, \mathrm{p}>0.1)$. Living in the central regions of Italy was positively associated with the likelihood of living in the same house with at least one grandchild at all time points. Socio-economic indicators (education, employment, and income) suggest that higher educated grandparents and those having an income were significantly less likely to coreside with their grandchildren at each survey considerd compared to grandparents with low 
levels of educations and those without an income, while being in paid work was associated with higher likelihood of coresidence with grandchildren only in 1998 and 2003. Moreover, having chronic conditions or disabilities was associated with an increase of about 2 percentage points in the probability of living with at least one grandchild only in 2009 and in 2016 . Finally, although the effect is minimal, the number of grandchildren was associated with increased likelihood of coresidence with at least one of them only in 1998.

In the last column of Table 2, p-values for the change in the parameters of the same variable over time are listed; these values are obtained from the interaction between each independent variable and the survey timing (1998 vs 2016). If the p-value is significant (i.e. <0.05), this suggests that the effect of the independent variable on the outcome considered was different in 2016 compared to 1998. According to this test, only the effects of age, marital status, and number of grandchildren were significantly different in 2016 compared to 1998. More in detail, compared with grandparents aged 50-59, those aged 60-74 and 75 and older were less likely to coreside in 2016 than in 1998 (see also Figure A.1, panel a in the Appendix). Similarly, respondents without a partner (widowed and never married/separated or divorced) were less likely to coreside with grandchildren in 2016 (Figure A.1, panel $b$ in the Appendix). Finally, while an increasing number of grandchildren was associated with a higher probability to coreside in 1998, respondents with a high number of grandchildren were less likely to do so in 2016 (Figure A.3, panel c in the Appendix).

[Table 2 about here]

\section{Face-to-face contact with grandchild(ren)}

Table 3 shows AMEs obtained from logistic models for daily contacts with at least one grandchild. Older age was negatively associated with daily contacts and, specifically, individuals aged 75+ were about 14 to 17 percentage points less likely to have face-to-face contacts with their grandchild(ren) compared to those aged 50-59. Widowhood and union dissolution were negatively associated with grandparents-grandchildren physical contacts. Widowed grandparents were about 6 (1998) to 3 (2016) percentage points less likely to have daily contacts with grandchild(ren), while divorced/separated or never married were between 10 (in 1998) to 13 (in 2016) percentage points less likely to have so. Living in the South was associated with higher probability to have face-to-face contacts. Regarding socio-economic characteristics, the negative association between higher educational attainment and the frequency of contacts with grandchildren lost magnitude and statistical power over time. In detail, findings show that respondents with at least a high-school degree were about 5 percentage points less likely to have daily contacts with grandchild(ren) in 1998 ( $<<0.001)$ and just about 3 percentage points less likely to have so in 2003 ( $\mathrm{p}<0.001)$, while this association was 
no longer statistically significant in 2009 and in 2016. Finally, while the number of grandchildren decreased the probability to have daily contacts with at least one of them, living close to them increased so. However, the association decreased of about 7 percentage points between 1998 and 2016.

According to the statistic test of changes in the association of each explanatory variables with the outcome over time (last column on Table 3), only the associations between respondents' education, proximity to grandchildren and daily face-to-face contacts with grandchild(ren) were significantly different in 2016 compared to 1998. Specifically, whereas highly educated grandparents were less likely to have daily face-to-face contacts with grandchildren in 1998 compared to those with lower levels of education (AMEs -0.059, p<0.001), no differences were found in 2016 suggesting that educational attainments have become less important in determining frequency of contacts with grandchildren (see also Figure A.2, panel a in the Appendix). Additionally, we found that living within $1 \mathrm{KM}$ was more relevant in determining daily contacts with grandchildren in 1998 (Figure A.2, panel $\mathrm{c}$ in the Appendix).

[Table 3 about here]

\section{Provision of grandparental childcare}

Findings for grandparental childcare provision are shown in Table 4, which lists AMEs, and robust standard errors drawn from multinomial predicted probabilities. While grandmothers were, overall, more likely to provide grandchildren care when parents work, older grandparents were less likely to provide so. Findings were significant for 1998, 2003 and 2009. However, these differences were not confirmed for caregiving during holidays. Grandparents living in the South were significantly less likely to provide intensive care to grandchildren (i.e., when parents work) in all the considered time periods. The probability to provide care when parents work (vs providing it ocassionally) was significantly lower for higher educated respondents in 1998. However, this association has decreased its magnitude and its statistical power over time ( $>>0.1$ ), becoming positive in 2009 and in 2016 $(\mathrm{p}>0.1)$. Grandparents who were active in the job market were also less likely to provide care when parents work, although the association changed sign and lost power in 2016 ( $>0.1)$. Number of grandchildren was negatively associated with care while living close to them increased respondent's probability to provide grandchild care when parents work.

With regard to holidays caregivers, widowed grandparents were about 2 to 3 percentage points less likely to provide grandchild care during holidays in 1998 and in 2003. However, while union dissolution was negatively associated with grandchild care during holidays in 1998, separated or 
divorced grandparents were about 4 percentage points more likely to provide grandchild(ren) care during holidays in 2003. In addition, our findings suggest that higher educated grandparents were more likely to provide care during 2016 (AMEs $=0.028, \mathrm{p}<0.01)$. Grandparents living in the South were more likely to provide care during holidays in 2003 (AMEs $=0.064 ; \mathrm{p}<0.001$ ), in 2009 (AMEs $=0.039 ; \mathrm{p}<0.001)$ and in 2016 (AMEs $=0.047 ; \mathrm{p}<0.001)$. Finally, respondents living within $1 \mathrm{Km}$ from their grandchild(ren) were between 30 to 42 percentage points less likely to provide care during holidays.

In terms of changes of associations between socio-demographic factors and grandchild caregiving during holidays, we observe a variation in its association with education $(p<0.001)$, being widow and divorced/never married $(\mathrm{p}<0.01)$ and living in Central Italy $(\mathrm{p}<0.001)$ over the last 20 years (Figure A.3 in the Appendix). With regard to grandchild caregiving when parents work, over the last 20 years, education, working status and having own income were more relevant in 2016 compared with 1998 (Figure A.4 in the Appendix).

[Table 4 about here]

As a robustness check, we have replicated all analyses on a sub-sample consisting of grandparents aged 60+. Results (available upon request) are consistent with those provided by the main analyses.

Table 5 summarises the main findings by respectively listing changes in the grandparents' characteristics over time (i.e., changes in the structure - RQ1) and changes in the association between grandparents' characteristics and grandparent-grandchild interactions (i.e., changes in the association - RQ2). More specifically, in the table we report the directions ( $\Uparrow$ : increase; $\Downarrow$ : decrease of the effects in 2016 compared to 1998) and the statistical significance of changes between 1998 and 2016.

[Table 5 about here]

\section{Conclusions and Discussion}

This study has assessed changes in grandparent-grandchildren relationships over two decades in Italy. More specifically, we have examined the trend over time of coresidence, face-to-face contacts and grandparental childcare as well as their (change in the) association with individual socio-economic and demographic factors.

Overall, despite the socio-demographic changes observed among grandparents between 1998 and 2016 (with grandparents becoming older, having fewer grandchildren and more of them living farther 
away, and higher levels of education), their involvement in their grandchildren's life has changed little. Empirical findings have shown that exchanges between grandparents and grandchildren remained broadly stable over the twenty years considered, with a slight decrease in daily face-to-face contacts and a slight increase in the proportion of grandparents providing grandchild care. The finding related to face-to-face contacts, however, should be considered in light of increases in the use of alternative means of communication (see Arpino et a. 2021). For instance, in the 2016 survey - the only one to include questions on contacts by modern technology such as video calls - we found that $2.15 \%$ of grandparents had daily digital communication with their grandchildren and $3 \%$ at least weekly. These proportions rise to $4.3 \%$ and $8.8 \%$ respectively when grandparents live more than 16 $\mathrm{km}$ away, suggesting that when the possibility of face-to-face contacts are limited by distance (or for example when mobility is restricted as during the recent COVID pandemic), grandparents may use other means of communication to keep in regular contact with their grandchildren.

Previous studies on socio-demographic changes that occurred in recent decades among older people and their theoretical importance in shaping intergenerational relationships, have found relatively stable exchanges (Steinbach et al. 2020, Kalmijn and De Vries 2009, Treas and Guberskaya 2012), and strong resilience in relationships between older parents and their adult children measured using frequency of contacts, rating of affections, or reciprocity. Using the German Ageing Study, Steinbach and colleagues (2020) explained this stability hypothesising that "family members appear to react to variations in social and economic circumstances with behavioural changes allowing them to maintain high levels of overall intergenerational solidarity (p.904)". Using data from the International Social Survey Programme, both Kalmijn and De Vries (2009) and Treas and Guberskaya (2012) also found that changes in population composition played a marginal role on changes in intergenerational exchanges, and that overall there was no evidence that adult children's contact with mothers had become less frequent over time. These results, mainly involving G1- G2 exchanges, seem to hold when G1-G3 exchanges are considered as in this work.

Our study confirms how intergenerational family relations have been characterised by stability rather than change, and that few changes were mostly driven by behavioural rather than compositional changes in the population (e.g., Steinbach et al. 2019). Also in our study we found that most characteristics have remained almost stable predictors of intergenerational exchanges over time, with few exceptions. For instance, when contacts were considered, divorced/separated/never married grandparents and those living far away from their grandchildren were less likely to have daily contacts with them, across all time points. In Italy, to date, the (small) rise in divorce which has generally been associated with weaker grandparent-grandchild relationships, especially on the paternal side (Westphal et al. 2015), has not yet adversely impacted intergenerational relationships between 
grandparents and grandchildren. However, older grandparents are generally less likely to have daily face-to-face contacts with their grandchildren and have become less likely to coreside with them. Therefore, it is likely that as older people move to grandparenthood later in life (Di Gessa et al, 2020a) there will be an impact on co-residence and face-to-face contacts. Moreover, the negative associations between higher educational attainment and both daily contacts with grandchildren and intensive grandchild care provision lost their statistical power over time, with even a positive sign in 2016. Thus, we could expect that the increase in grandparents' level of education will not affect their relations with grandchildren in the future. Additionally, the lower number of grandchildren experienced by the new cohorts of older people may facilitate intensive intergenerational exchanges.

This study draws strength from using data from nationally-representative data of high quality and good response rates. It also explored a variety of currencies of exchanges over time among grandparents and grandchildren in Italy. Moreover, we investigated changes in the associations between socio-demographic factors and intergenerational exchanges in an attempt to understand whether and to what extent societal changes are a driving force of these observed trends. Our contribution, however, should be considered in light of some limitations. By design, it is not possible to link grandchildren to their parents's socio-demographic characteristics: therefore, we could not account for important confounders such as parents' employment or marital status. Furthermore, no information on formal childcare availability and/or use is collected and, as mentioned above, questions on communications by modern technologies were included only in the most recent survey. As the number of foreign-born grandparents is increasing in Italy, further studies should investigate changes in this subgroup and between Italian and non-Italian grandparents. Finally, some measures, particularly the health indicator, required adaptation whereas others (such as wealth or home tenure) were not collected across all four surveys and could not be used in our analysis.

In conclusion, despite important demographic and societal changes among Italian grandparents in the first two decades of the $21^{\text {st }}$ century, grandparents continue to show generally a very high and resilient level of interactions with their grandchildren, with little evidence to support potential concerns of a decline in intergenerational exchanges. 
Table 1. Weighted Descriptive characteristics of respondents by year

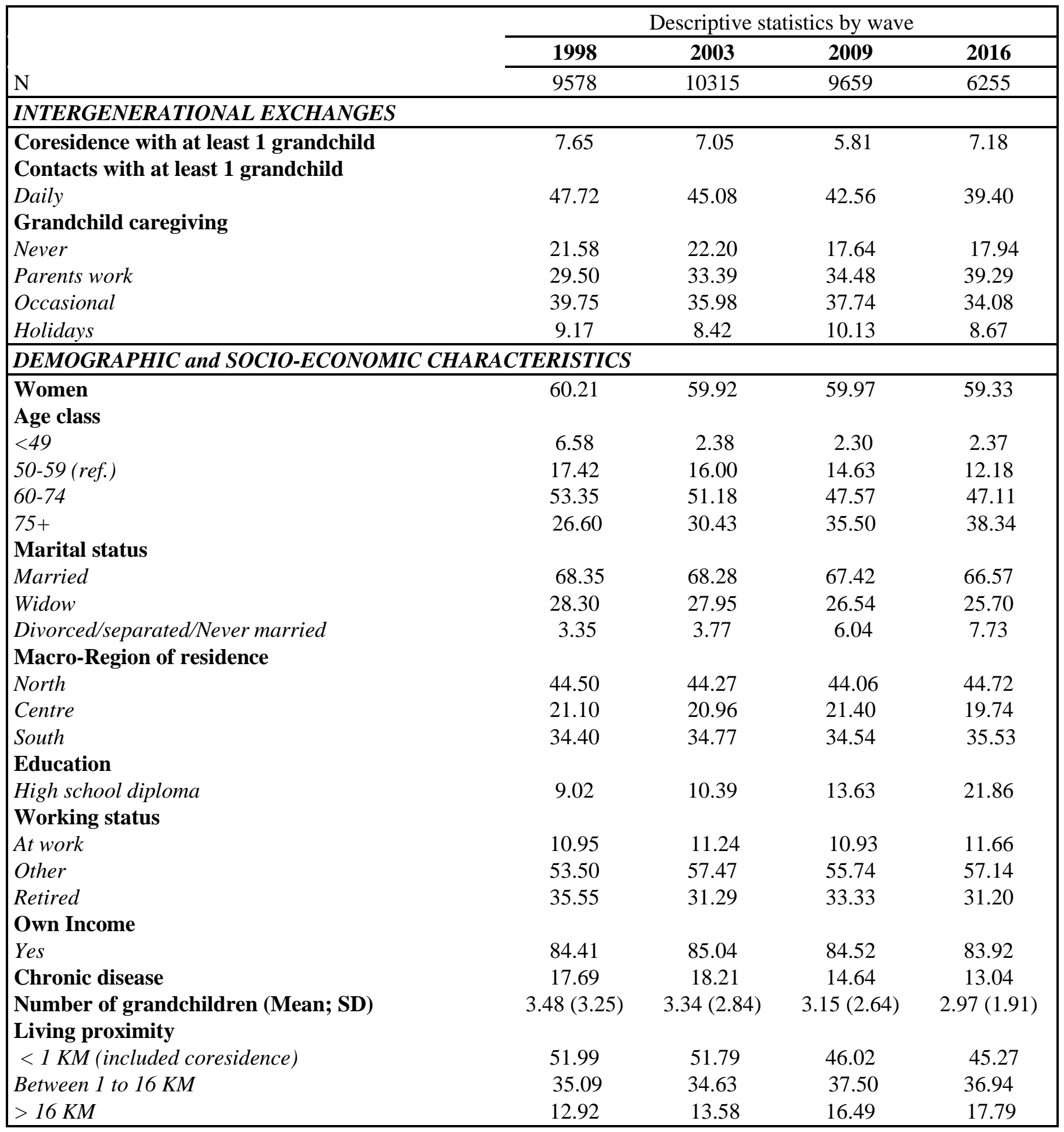

Source: Family and Social Subjects (FSS) Survey, ISTAT. Weighted data. 
Table 2. Logistic regression models estimating the Average Marginal Effects (AMEs) of having at least one coresident grandchild among all grandparents by year.

\begin{tabular}{|c|c|c|c|c|c|}
\hline \multirow{3}{*}{ Variables } & \multicolumn{5}{|c|}{ Coresidence - Logit AMEs (SE) } \\
\hline & \multicolumn{4}{|c|}{ With at least one grandchild } & \multirow{2}{*}{$\begin{array}{l}\frac{\chi^{2} \text { фо } \rho \mathrm{H}_{0}:}{\beta_{1998}=\beta_{2016}} \\
\mathrm{P}\end{array}$} \\
\hline & 1998 & 2003 & 2009 & 2016 & \\
\hline Women & $\begin{array}{c}0.000 \\
(0.007)\end{array}$ & $\begin{array}{l}-0.000 \\
(0.006)\end{array}$ & $\begin{array}{l}-0.012 * * \\
(0.006)\end{array}$ & $\begin{array}{l}-0.007 \\
(0.007)\end{array}$ & n.s \\
\hline Age class $<49$ (ref. 50-59) & $\begin{array}{c}0.066^{* * *} \\
(0.023)\end{array}$ & $\begin{array}{c}0.052 * * * \\
(0.022)\end{array}$ & $\begin{array}{c}0.096 * * * \\
(0.028)\end{array}$ & $\begin{array}{c}0.144 * * * \\
(0.048)\end{array}$ & n.s \\
\hline Age class 60-74 (ref. 50-59) & $\begin{array}{l}-0.004 \\
(0.009)\end{array}$ & $\begin{array}{l}-0.007 \\
(0.007)\end{array}$ & $\begin{array}{c}-0.025 * * * \\
(0.010)\end{array}$ & $\begin{array}{c}-0.060 * * * \\
(0.016)\end{array}$ & $* * *$ \\
\hline Age class $75+($ ref. $50-59)$ & $\begin{array}{c}0.032 * * * \\
(0.011)\end{array}$ & $\begin{array}{l}0.022 * * \\
(0.010)\end{array}$ & $\begin{array}{l}-0.023 \\
(0.011)\end{array}$ & $\begin{array}{c}-0.062 * * * \\
(0.018)\end{array}$ & $* * *$ \\
\hline Widow (ref. Married) & $\begin{array}{c}0.121 * * * \\
(0.010)\end{array}$ & $\begin{array}{c}0.079 * * * \\
(0.008)\end{array}$ & $\begin{array}{c}0.085^{* * *} \\
(0.009)\end{array}$ & $\begin{array}{c}0.046^{* * *} \\
(0.011)\end{array}$ & $* * *$ \\
\hline $\begin{array}{l}\text { Divorced/separated/Never married (ref. } \\
\text { Married) }\end{array}$ & $\begin{array}{c}0.047 * * \\
(0.018)\end{array}$ & $\begin{array}{c}0.028 * * \\
(0.013)\end{array}$ & $\begin{array}{c}0.039 * * * \\
(0.011)\end{array}$ & $\begin{array}{l}-0.006 \\
(0.009)\end{array}$ & $* *$ \\
\hline Macro Region of residence: Centre (ref. North) & $\begin{array}{c}0.061 * * * \\
(0.008)\end{array}$ & $\begin{array}{c}0.027 * * * \\
(0.007)\end{array}$ & $\begin{array}{c}0.026^{* * *} \\
(0.007)\end{array}$ & $\begin{array}{c}0.053 * * * \\
(0.010)\end{array}$ & n.s \\
\hline Macro Region of residence: South (ref. North) & $-0.014 * *$ & -0.005 & -0.004 & -0.001 & n.s \\
\hline High school diploma & $\begin{array}{c}-0.041 * * * \\
(0.163) \\
(0.006)\end{array}$ & $\begin{array}{c}-0.036 * * * \\
(0.010) \\
(0.005)\end{array}$ & $\begin{array}{l}-0.006 \\
(0.008) \\
(0.005)\end{array}$ & $\begin{array}{c}-0.020 * * \\
(0.008) \\
(0.006)\end{array}$ & n.s \\
\hline Working status: Working (ref. Retired) & $\begin{array}{l}0.026^{*} \\
(0.015)\end{array}$ & $\begin{array}{c}0.044 * * * \\
(0.014)\end{array}$ & $\begin{array}{c}0.009 \\
(0.011)\end{array}$ & $\begin{array}{c}0.006 \\
(0.013)\end{array}$ & n.s \\
\hline Working status: Other (ref. Retired) & $\begin{array}{l}-0.001 \\
(0.007)\end{array}$ & $\begin{array}{l}0.011 * \\
(0.006)\end{array}$ & $\begin{array}{l}-0.005 \\
(0.006)\end{array}$ & $\begin{array}{c}0.008 \\
(0.009)\end{array}$ & n.s \\
\hline Own income & $\begin{array}{l}-0.018 \\
(0.011)\end{array}$ & $\begin{array}{c}-0.032 * * * \\
(0.010)\end{array}$ & $\begin{array}{c}-0.020 * * \\
(0.008)\end{array}$ & $\begin{array}{l}-0.022 * \\
(0.012)\end{array}$ & n.s \\
\hline Chronic conditions & $\begin{array}{c}0.012 \\
(0.007)\end{array}$ & $\begin{array}{c}0.006 \\
(0.006)\end{array}$ & $\begin{array}{c}0.018 * * * \\
(0.006)\end{array}$ & $\begin{array}{c}0.019 * * \\
(0.009)\end{array}$ & n.s \\
\hline Number of grandchildren & $\begin{array}{c}0.003 * * * \\
(0.000)\end{array}$ & $\begin{array}{c}0.001 \\
(0.000)\end{array}$ & $\begin{array}{c}0.001 \\
(0.000)\end{array}$ & $\begin{array}{l}-0.002 \\
(0.001)\end{array}$ & $* * *$ \\
\hline Observations & 9,578 & 10,315 & 9,659 & 5,893 & \\
\hline
\end{tabular}

Source: Family and Social Subjects (FSS) Survey, ISTAT

Note: $* \mathrm{p}<0.05 ; * * \mathrm{p}<0.01 ; * * * \mathrm{p}<0.001$. n.s. $=$ not sugnificant. 
Table 3. Logistic regression models estimating the Average Marginal Effects (AMEs) of daily contacts with grandchild among all grandparents by year.

\begin{tabular}{|c|c|c|c|c|c|}
\hline \multirow{3}{*}{ Variables } & \multicolumn{5}{|c|}{ Face to face contacts - Logit AMEs (SE) } \\
\hline & \multicolumn{4}{|c|}{ Daily vs Less often } & \multirow{2}{*}{$\begin{array}{c}\chi^{2} \phi_{\text {фо } \rho \mathrm{H}_{0}} \\
\beta_{98}=\beta_{16}\end{array}$} \\
\hline & 1998 & 2003 & 2009 & 2016 & \\
\hline Women & $\begin{array}{c}0.012 \\
(0.011)\end{array}$ & $\begin{array}{c}0.008 \\
(0.010)\end{array}$ & $\begin{array}{c}0.010 \\
(0.010)\end{array}$ & $\begin{array}{l}-0.000 \\
(0.013)\end{array}$ & n.s \\
\hline Age class $<49$ (ref. 50-59) & $\begin{array}{l}-0.005 \\
(0.027)\end{array}$ & $\begin{array}{l}-0.029 \\
(0.030)\end{array}$ & $\begin{array}{c}0.009 \\
(0.034)\end{array}$ & $\begin{array}{l}-0.080 \\
(0.056)\end{array}$ & n.s \\
\hline Age class 60-74 (ref. 50-59) & $\begin{array}{c}-0.071 * * * \\
(0.012)\end{array}$ & $\begin{array}{c}-0.064 * * * \\
(0.013)\end{array}$ & $\begin{array}{c}-0.041 * * * \\
(0.015)\end{array}$ & $\begin{array}{c}-0.047 * * \\
(0.021)\end{array}$ & n.s \\
\hline Age class $75+($ ref. $50-59)$ & $\begin{array}{c}-0.166^{* * *} \\
(0.016)\end{array}$ & $\begin{array}{c}-0.148 * * * \\
(0.016)\end{array}$ & $\begin{array}{c}-0.173 * * * \\
(0.017)\end{array}$ & $\begin{array}{c}-0.150 * * * \\
(0.024)\end{array}$ & n.s \\
\hline Widow (ref. Married) & $\begin{array}{c}-0.066^{* * *} \\
(0.012)\end{array}$ & $\begin{array}{c}-0.051 * * * \\
(0.011)\end{array}$ & $\begin{array}{c}-0.042 * * * \\
(0.012)\end{array}$ & $\begin{array}{c}-0.033 * \\
(0.015)\end{array}$ & n.s \\
\hline Divorced/separated/Never married (ref. Married) & $\begin{array}{c}-0.104 * * \\
(0.028)\end{array}$ & $\begin{array}{c}-0.069 * * * \\
(0.025)\end{array}$ & $\begin{array}{c}-0.128 * * * \\
(0.021)\end{array}$ & $\begin{array}{c}-0.137 * * * \\
(0.023)\end{array}$ & n.s \\
\hline Macro Region of residence: Centre (ref. North) & $\begin{array}{c}0.016 \\
(0.011)\end{array}$ & $\begin{array}{l}-0.004 \\
(0.011)\end{array}$ & $\begin{array}{c}0.003 \\
(0.012)\end{array}$ & $\begin{array}{c}0.023 \\
(0.016)\end{array}$ & n.s \\
\hline Macro Region of residence: South (ref. North) & $\begin{array}{c}0.037 * * * \\
(0.010)\end{array}$ & $\begin{array}{c}0.029 * * * \\
(0.010)\end{array}$ & $\begin{array}{c}0.035^{* * *} \\
(0.010)\end{array}$ & $\begin{array}{c}0.052 * * * \\
(0.013)\end{array}$ & n.s \\
\hline High school diploma & $\begin{array}{c}-0.059 * * * \\
(0.016)\end{array}$ & $\begin{array}{c}-0.030 * * \\
(0.015)\end{array}$ & $\begin{array}{l}-0.014 \\
(0.014)\end{array}$ & $\begin{array}{l}-0.002 \\
(0.014)\end{array}$ & $* * *$ \\
\hline Working status: Working (ref. Retired) & $\begin{array}{l}-0.002 \\
(0.019)\end{array}$ & $\begin{array}{l}-0.016 \\
(0.019)\end{array}$ & $\begin{array}{l}-0.021 \\
(0.019)\end{array}$ & $\begin{array}{c}0.010 \\
(0.025)\end{array}$ & n.s \\
\hline Working status: Other (ref. Retired) & $\begin{array}{l}0.022 * \\
(0.012)\end{array}$ & $\begin{array}{l}-0.001 \\
(0.013)\end{array}$ & $\begin{array}{c}0.014 \\
(0.012)\end{array}$ & $\begin{array}{c}0.031 * * \\
(0.017)\end{array}$ & n.s \\
\hline Own income & $\begin{array}{c}0.016 \\
(0.016)\end{array}$ & $\begin{array}{c}0.024 \\
(0.017)\end{array}$ & $\begin{array}{c}0.021 \\
(0.016)\end{array}$ & $\begin{array}{c}0.003 \\
(0.022)\end{array}$ & n.s \\
\hline Chronic conditions & $\begin{array}{c}-0.048 * * * \\
(0.012)\end{array}$ & $\begin{array}{c}-0.035 * * * \\
(0.012)\end{array}$ & $\begin{array}{l}-0.016 \\
(0.012)\end{array}$ & $\begin{array}{c}-0.049 * * * \\
(0.017)\end{array}$ & n.s \\
\hline Number of grandchildren & $\begin{array}{c}-0.010 * * * \\
(0.001)\end{array}$ & $\begin{array}{c}-0.013 * * * \\
(0.001)\end{array}$ & $\begin{array}{c}-0.009 * * * \\
(0.001)\end{array}$ & $\begin{array}{c}-0.013 * * * \\
(0.003)\end{array}$ & n.s \\
\hline $\begin{array}{l}\text { Living proximity with grandchildren }:<1 \mathrm{Km} \text { (ref. }> \\
16 \mathrm{Km})\end{array}$ & $\begin{array}{c}0.684 * * * \\
(0.008)\end{array}$ & $\begin{array}{c}0.639 * * * \\
(0.008)\end{array}$ & $\begin{array}{c}0.651^{* * * *} \\
(0.008)\end{array}$ & $\begin{array}{c}0.614^{* * *} \\
(0.010)\end{array}$ & n.s \\
\hline between 1 to $16 \mathrm{Km}$ (ref. > $16 \mathrm{Km})$ & $\begin{array}{c}0.280 * * * \\
(0.009)\end{array}$ & $\begin{array}{c}0.286^{* * *} \\
(0.009)\end{array}$ & $\begin{array}{c}0.278 * * * \\
(0.008)\end{array}$ & $\begin{array}{c}0.286^{* * * *} \\
(0.011)\end{array}$ & $* *$ \\
\hline Observations & 9,103 & 9,921 & 9,318 & 5,634 & \\
\hline
\end{tabular}

Source: Family and Social Subjects (FSS) Survey, ISTAT

Note: $* \mathrm{p}<0.05 ; * * \mathrm{p}<0.01 ; * * * \mathrm{p}<0.001$. n.s. $=$ not significant. 
Table 4. Multinomial logistic regression models estimating the Average Marginal Effects (AMEs) of grandchild caregiving among all grandparents by year.

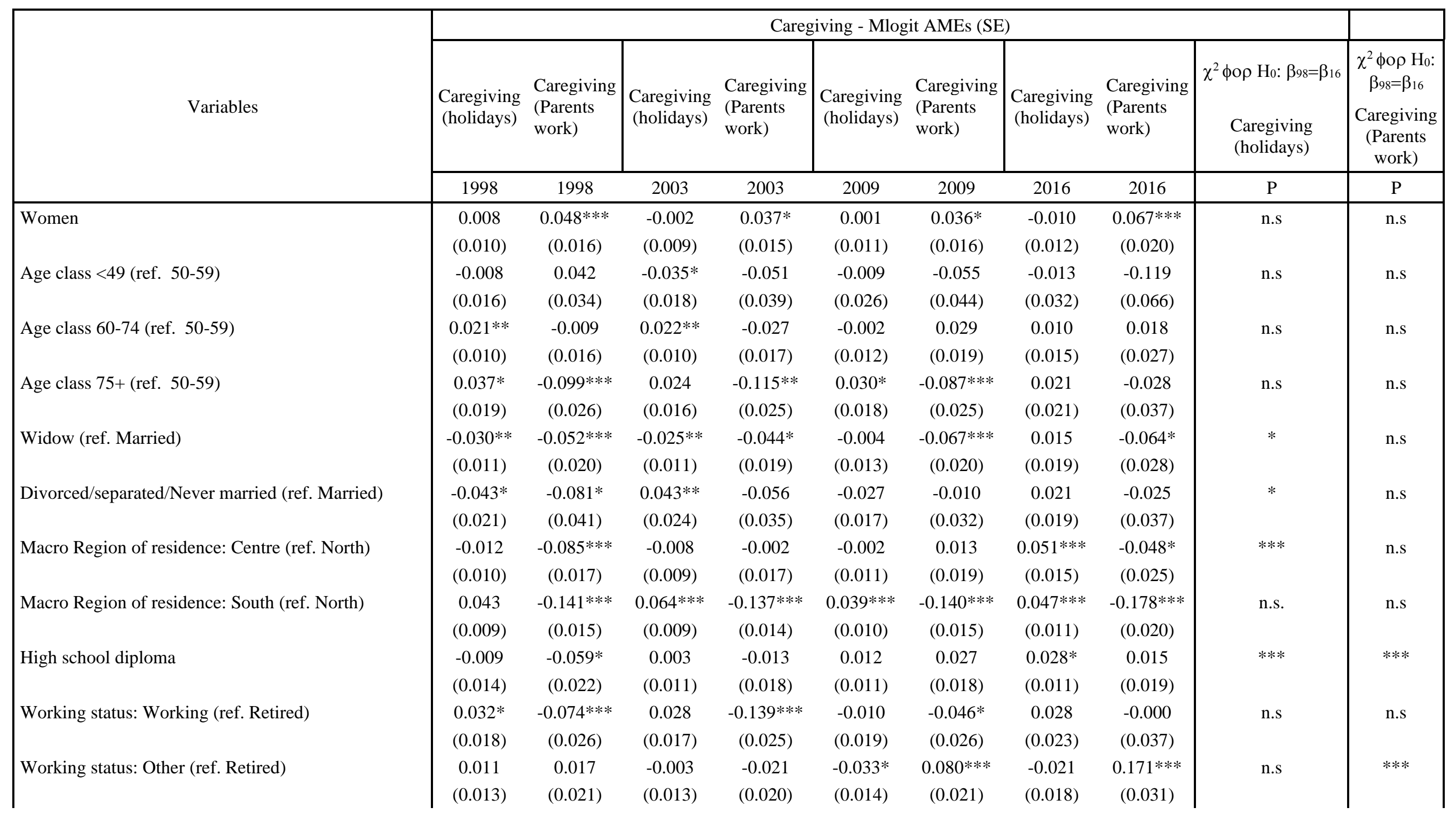




\begin{tabular}{|c|c|c|c|c|c|c|c|c|c|c|}
\hline \multicolumn{11}{|l|}{ Table 4, continued } \\
\hline Own income & $\begin{array}{l}-0.003 \\
(0.015)\end{array}$ & $\begin{array}{c}0.044 * * \\
(0.024)\end{array}$ & $\begin{array}{c}0.008 \\
(0.015)\end{array}$ & $\begin{array}{l}0.049^{*} \\
(0.025)\end{array}$ & $\begin{array}{c}0.019 \\
(0.015)\end{array}$ & $\begin{array}{l}-0.016 \\
(0.024)\end{array}$ & $\begin{array}{c}0.022 \\
(0.022)\end{array}$ & $\begin{array}{c}-0.103 * * * \\
(0.037)\end{array}$ & n.s & $* * *$ \\
\hline Chronic conditions & $\begin{array}{c}0.006 \\
(0.014)\end{array}$ & $\begin{array}{l}-0.020 \\
(0.022)\end{array}$ & $\begin{array}{c}0.019 \\
(0.013)\end{array}$ & $\begin{array}{l}-0.025 \\
(0.023)\end{array}$ & $\begin{array}{l}-0.014 \\
(0.016)\end{array}$ & $\begin{array}{c}0.015 \\
(0.023)\end{array}$ & $\begin{array}{l}0.052 * \\
(0.020)\end{array}$ & $\begin{array}{l}-0.038 \\
(0.039)\end{array}$ & n.s & $\mathrm{n} . \mathrm{s}$ \\
\hline Number of grandchildren & $\begin{array}{l}-0.001 \\
(0.001)\end{array}$ & $\begin{array}{c}-0.013 * * * \\
(0.003)\end{array}$ & $\begin{array}{c}0.002 \\
(0.001)\end{array}$ & $\begin{array}{c}-0.012 * * * \\
(0.003)\end{array}$ & $\begin{array}{c}0.006 * * * \\
(0.002)\end{array}$ & $\begin{array}{c}-0.014 * * * \\
(0.003)\end{array}$ & $\begin{array}{c}0.002 \\
(0.003)\end{array}$ & $\begin{array}{l}-0.009 * \\
(0.005)\end{array}$ & n.s & n.s \\
\hline $\begin{array}{l}\text { Living proximity with grandchildren }:<1 \mathrm{Km} \text { (ref. }> \\
16 \mathrm{Km} \text { ) }\end{array}$ & $\begin{array}{c}-0.421^{* * *} \\
(0.021)\end{array}$ & $\begin{array}{c}0.333 * * * \\
(0.016)\end{array}$ & $\begin{array}{c}-0.376 * * * \\
(0.019)\end{array}$ & $\begin{array}{c}0.334 * * * \\
(0.016)\end{array}$ & $\begin{array}{c}-0.305^{* * * *} \\
(0.019)\end{array}$ & $\begin{array}{c}0.317 * * * \\
(0.017)\end{array}$ & $\begin{array}{c}-0.362 * * * \\
(0.023)\end{array}$ & $\begin{array}{c}0.350^{* * * *} \\
(0.022)\end{array}$ & n.s & n.s \\
\hline between 1 to $16 \mathrm{Km}$ (ref. > $16 \mathrm{Km}$ ) & $\begin{array}{c}-0.381 * * * \\
(0.021)\end{array}$ & $\begin{array}{c}0.218 * * * \\
(0.017)\end{array}$ & $\begin{array}{c}-0.343 * * * \\
(0.019)\end{array}$ & $\begin{array}{c}0.254 * * * \\
(0.017)\end{array}$ & $\begin{array}{c}-0.273 * * * \\
(0.020)\end{array}$ & $\begin{array}{c}0.212 * * * \\
(0.017)\end{array}$ & $\begin{array}{c}-0.356 * * * \\
(0.023)\end{array}$ & $\begin{array}{c}0.310^{* * * *} \\
(0.022)\end{array}$ & n.s & n.s \\
\hline Observations & 5,230 & 5,230 & 5,516 & 5,516 & 5,031 & 5,031 & 2,754 & 2,754 & & \\
\hline
\end{tabular}

Source: Family and Social Subjects (FSS) Survey, ISTAT

Note: $* \mathrm{p}<0.05 ; * * \mathrm{p}<0.01 ; * * * \mathrm{p}<0.001$. n.s. $=$ not significant. 
Table 5: Visual summary of main results (RQ1 and RQ2)

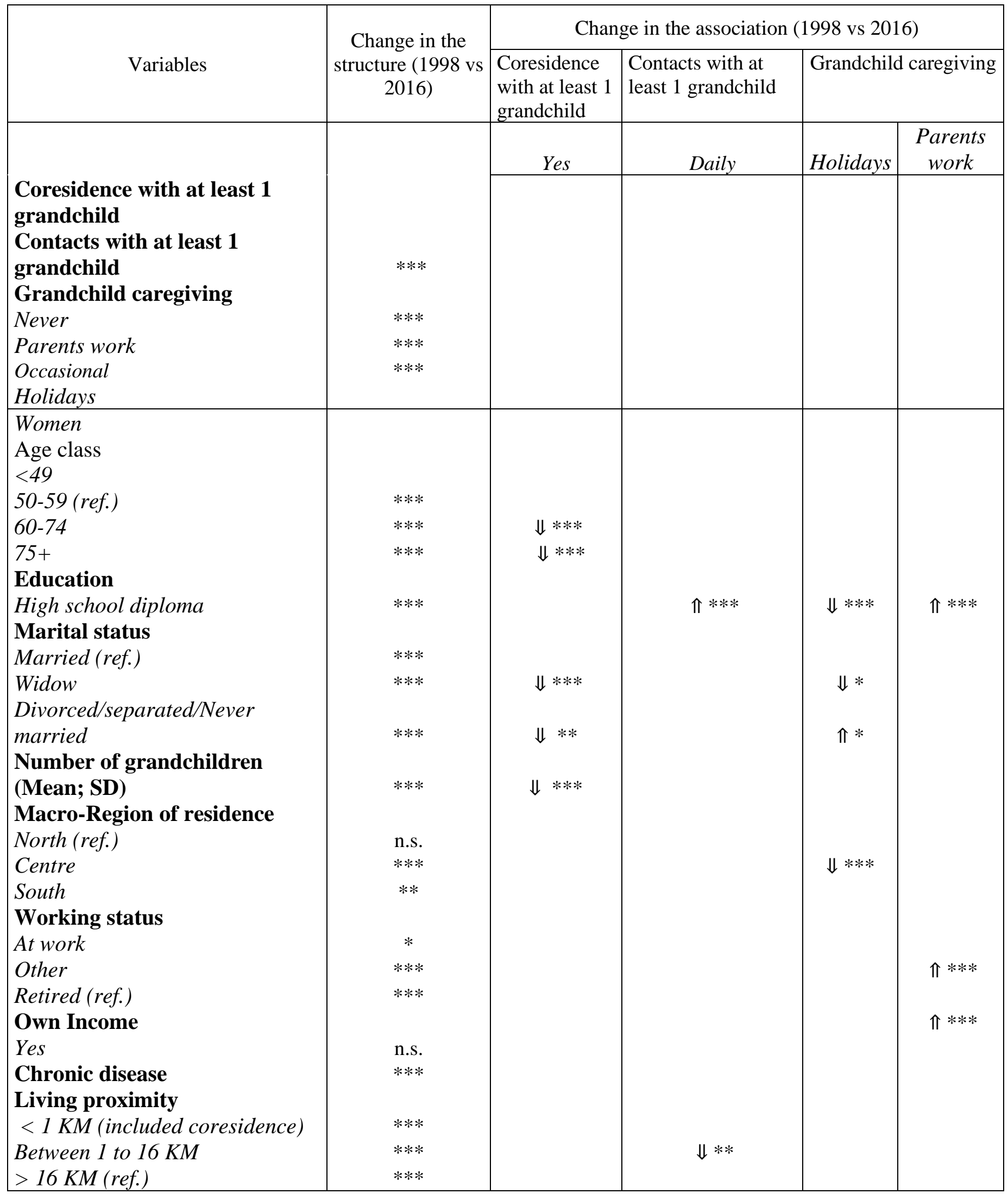

Note: $* \mathrm{p}<0.05 ; * * \mathrm{p}<0.01 ; * * * \mathrm{p}<0.001$. n.s. $=$ not significant; $\Downarrow$ if in 2016 the predicted value is lower than in 1998; $\pi$ if in 2016 the predicted value is higher than in 1998 
Appendix

Table A.1 Weighted Descriptive characteristics of respondents with grandchildren younger than 13 years old by year.

\begin{tabular}{|c|c|c|c|c|}
\hline \multirow[b]{2}{*}{$\mathrm{N}$} & 1998 & 2003 & 2009 & 2016 \\
\hline & 5451 & 5789 & 5199 & 2995 \\
\hline $\begin{array}{l}\text { Coresidence with at least } 1 \text { grandchild } \\
\text { Contacts with at least } 1 \text { grandchild }\end{array}$ & 3.14 & 2.61 & 2.68 & 2.83 \\
\hline $\begin{array}{l}\text { Daily } \\
\text { Grandchild caregiving }\end{array}$ & 52.37 & 49.63 & 47.68 & 44.81 \\
\hline Never & 21.58 & 22.20 & 17.64 & 17.94 \\
\hline Parents work & 29.50 & 33.39 & 34.48 & 39.29 \\
\hline Occasional & 39.75 & 35.98 & 37.74 & 34.08 \\
\hline Holidays & 9.17 & 8.42 & 10.13 & 8.67 \\
\hline Women & 57.38 & 56.34 & 57.15 & 55.43 \\
\hline Age class & & & & \\
\hline$<49$ & 3.55 & 2.99 & 2.79 & 2.37 \\
\hline 50-59 (ref.) & 25.95 & 23.65 & 20.68 & 19.35 \\
\hline $60-74$ & 61.71 & 61.61 & 60.43 & 63.94 \\
\hline $75+$ & 8.79 & 11.75 & 16.11 & 14.34 \\
\hline Marital status & & & & \\
\hline Married & 79.90 & 80.07 & 79.43 & 78.73 \\
\hline Widow & 17.90 & 15.88 & 15.10 & 13.23 \\
\hline Divorced/separated/Never married & 2.81 & 4.05 & 5.47 & 8.04 \\
\hline Macro-Region of residence & & & & \\
\hline North & 43.88 & 45.66 & 45.40 & 45.13 \\
\hline Centre & 19.85 & 19.48 & 19.80 & 19.77 \\
\hline South & 36.27 & 34.87 & 34.79 & 35.10 \\
\hline Education & & & & \\
\hline High school diploma & 10.69 & 12.84 & 17.20 & 28.42 \\
\hline Working status & & & & \\
\hline At work & 14.41 & 15.33 & 14.50 & 16.97 \\
\hline Other & 50.95 & 54.12 & 52.06 & 54.01 \\
\hline Retired & 34.64 & 30.55 & 33.44 & 29.02 \\
\hline Own Income & & & & \\
\hline Yes & 79.76 & 80.64 & 80.20 & 81.15 \\
\hline Chronic disease & 10.37 & 9.86 & 8.96 & 5.96 \\
\hline Number of grandchildren (Mean; SD) & $3.03(2.45)$ & $2.90(2.13)$ & $2.83(2.01)$ & $2.54(1.55)$ \\
\hline Living proximity & & & & \\
\hline < 1 KM (included coresidence) & 49.52 & 48.89 & 43.55 & 39.67 \\
\hline Between 1 to $16 \mathrm{KM}$ & 37.35 & 37.12 & 39.05 & 40.00 \\
\hline$>16 \mathrm{KM}$ & 13.13 & 13.99 & 17.39 & 20.33 \\
\hline
\end{tabular}

Source: Family and Social Subjects (FSS) Survey, ISTAT 
Figure A.1 Predicted Probabilities Coresidence - Changes over time

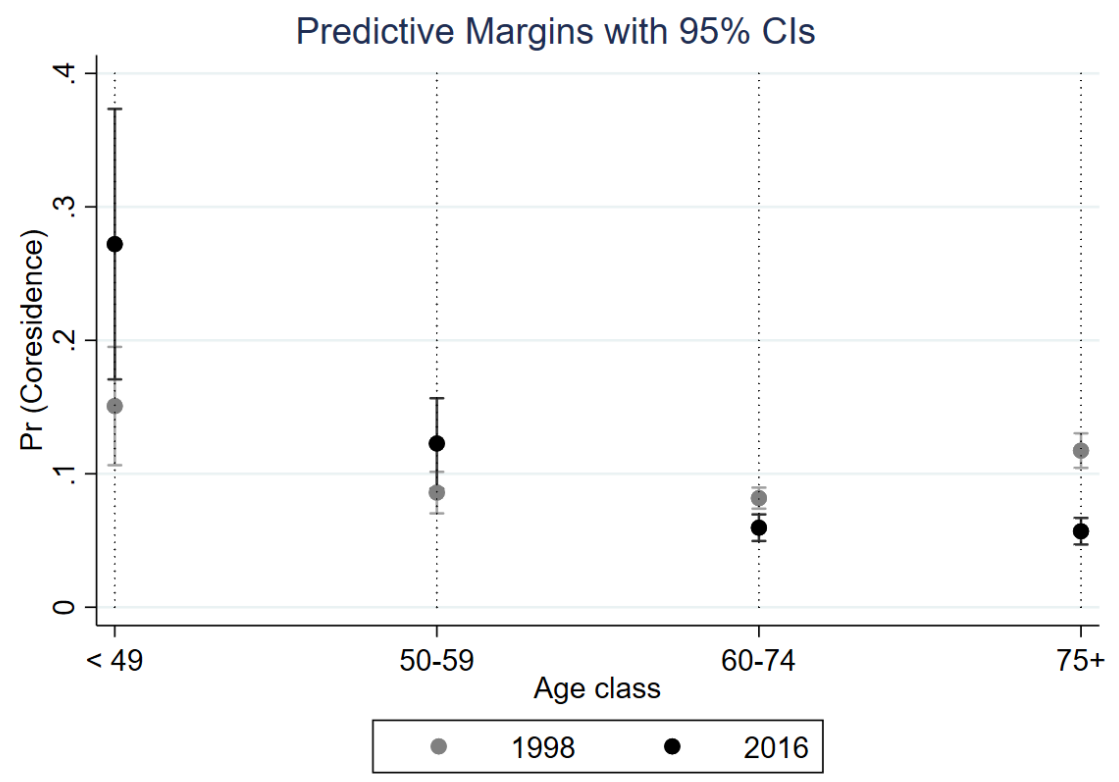

Panel a

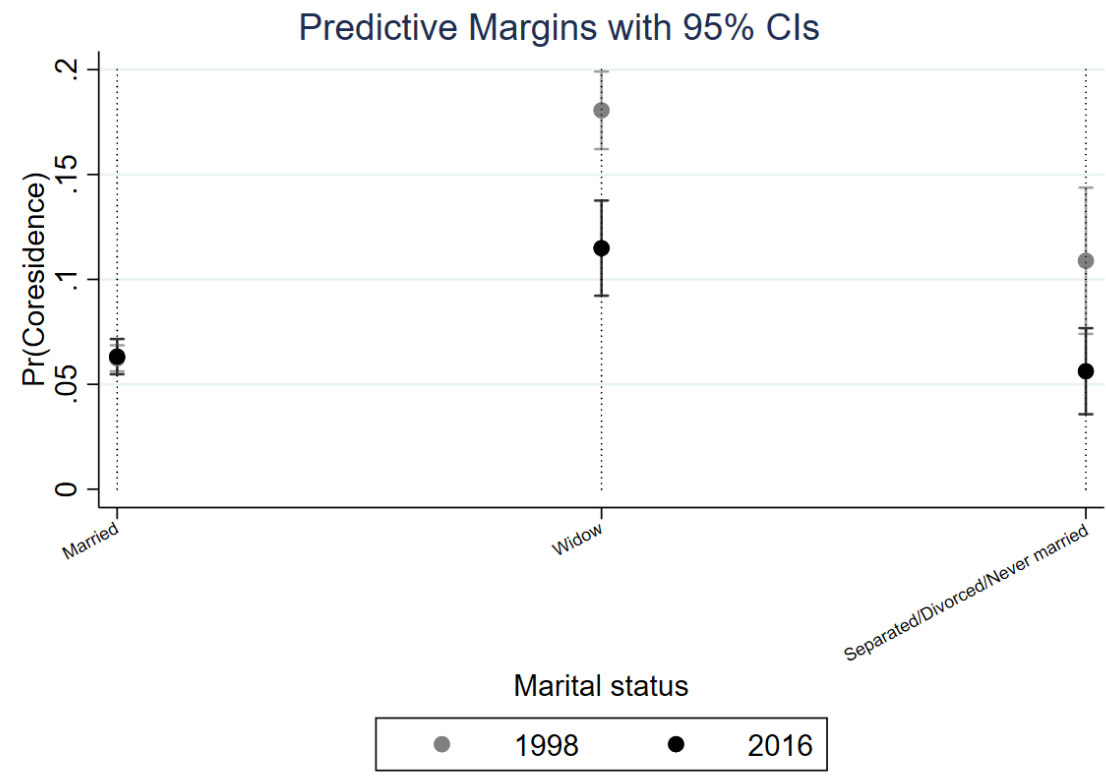

Panel b 


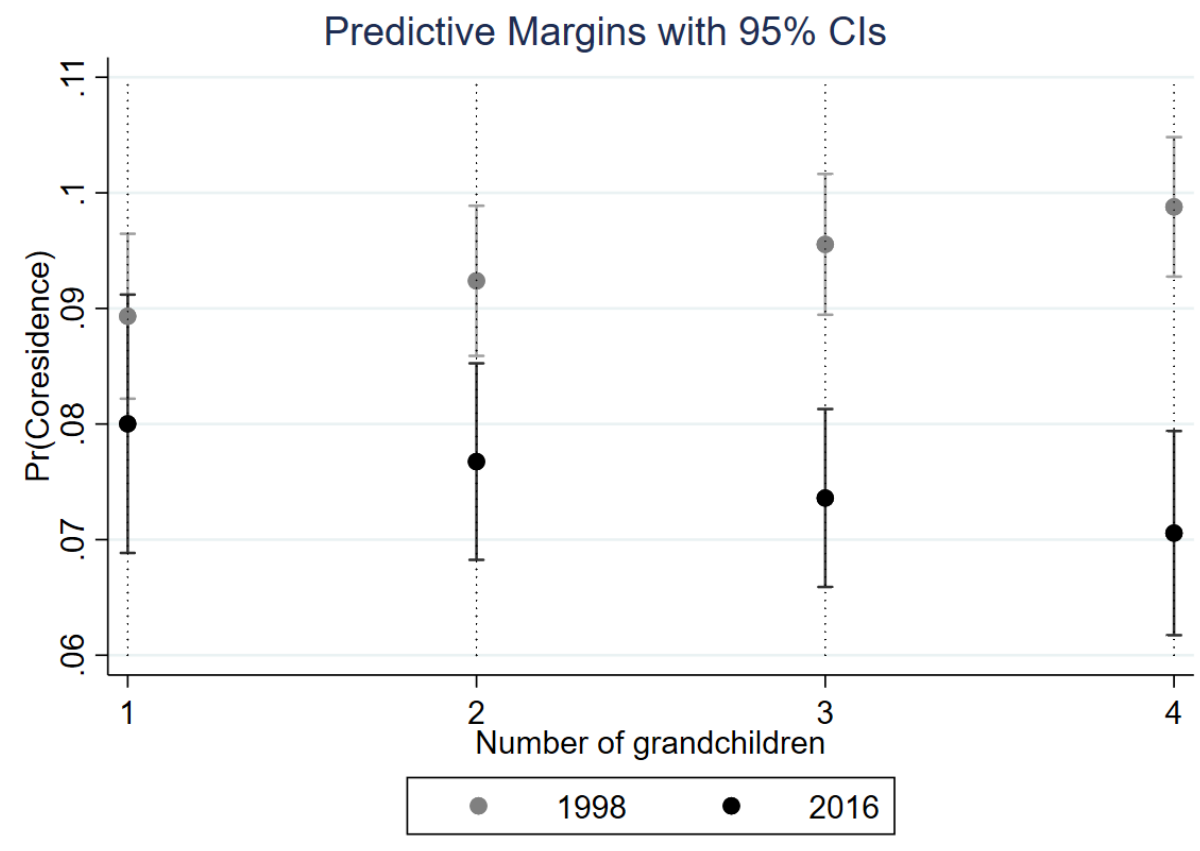

Panel c 
Figure A.2 Predicted Probabilities Daily contacts - Changes over time
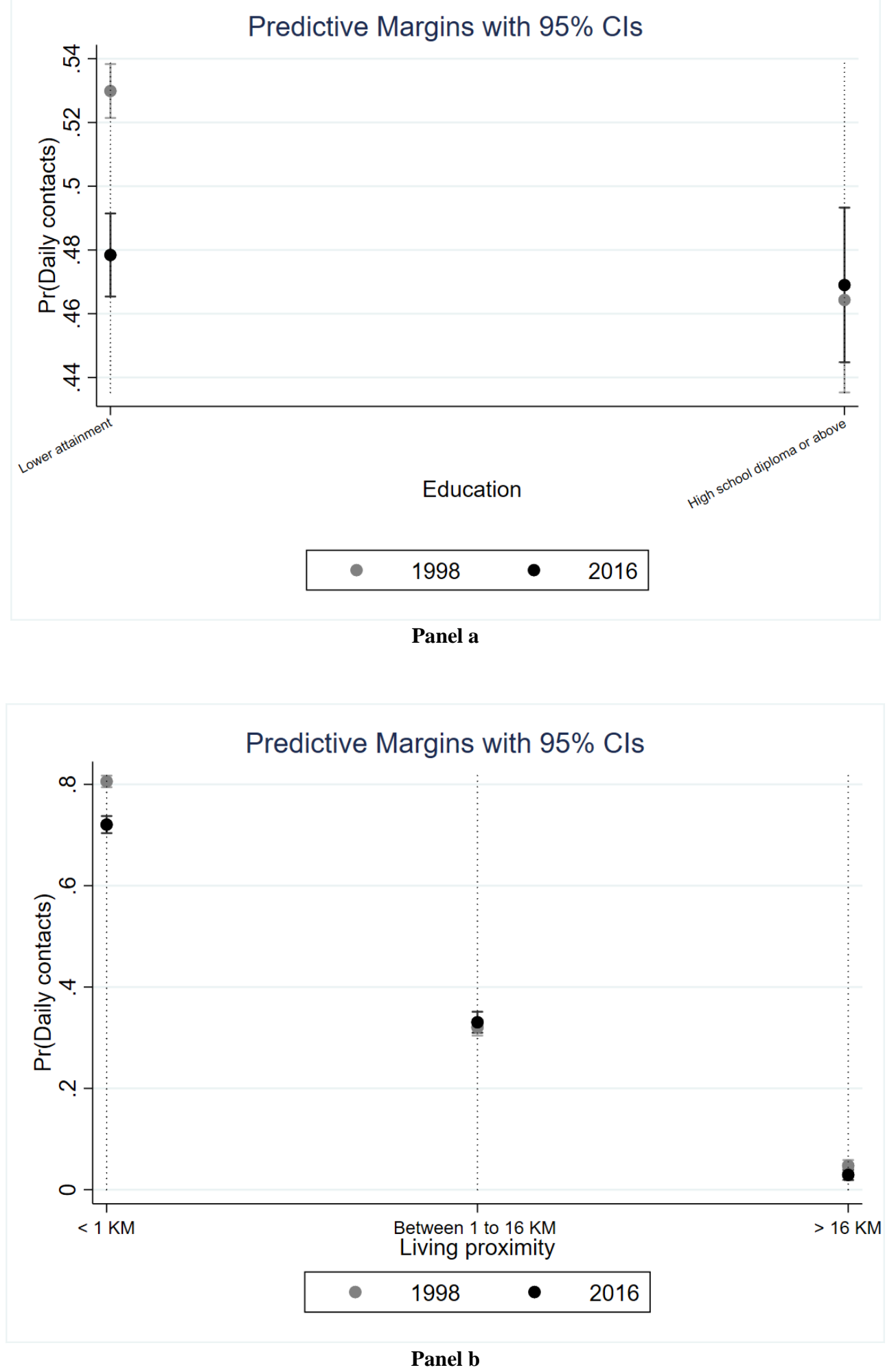
Figure A.3 Predicted Probabilities Grandchild Care during holidays - Changes over time
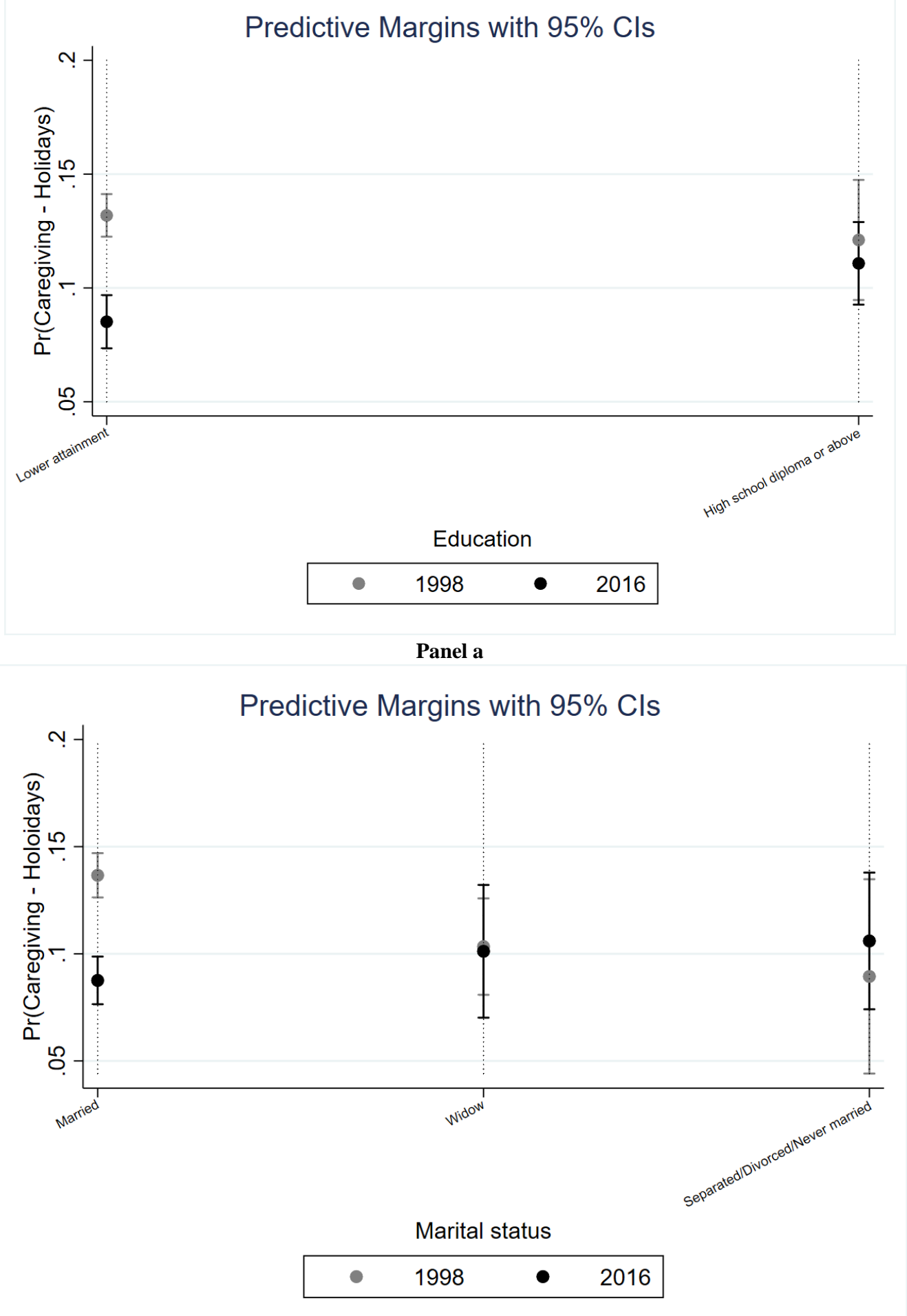

Panel b 


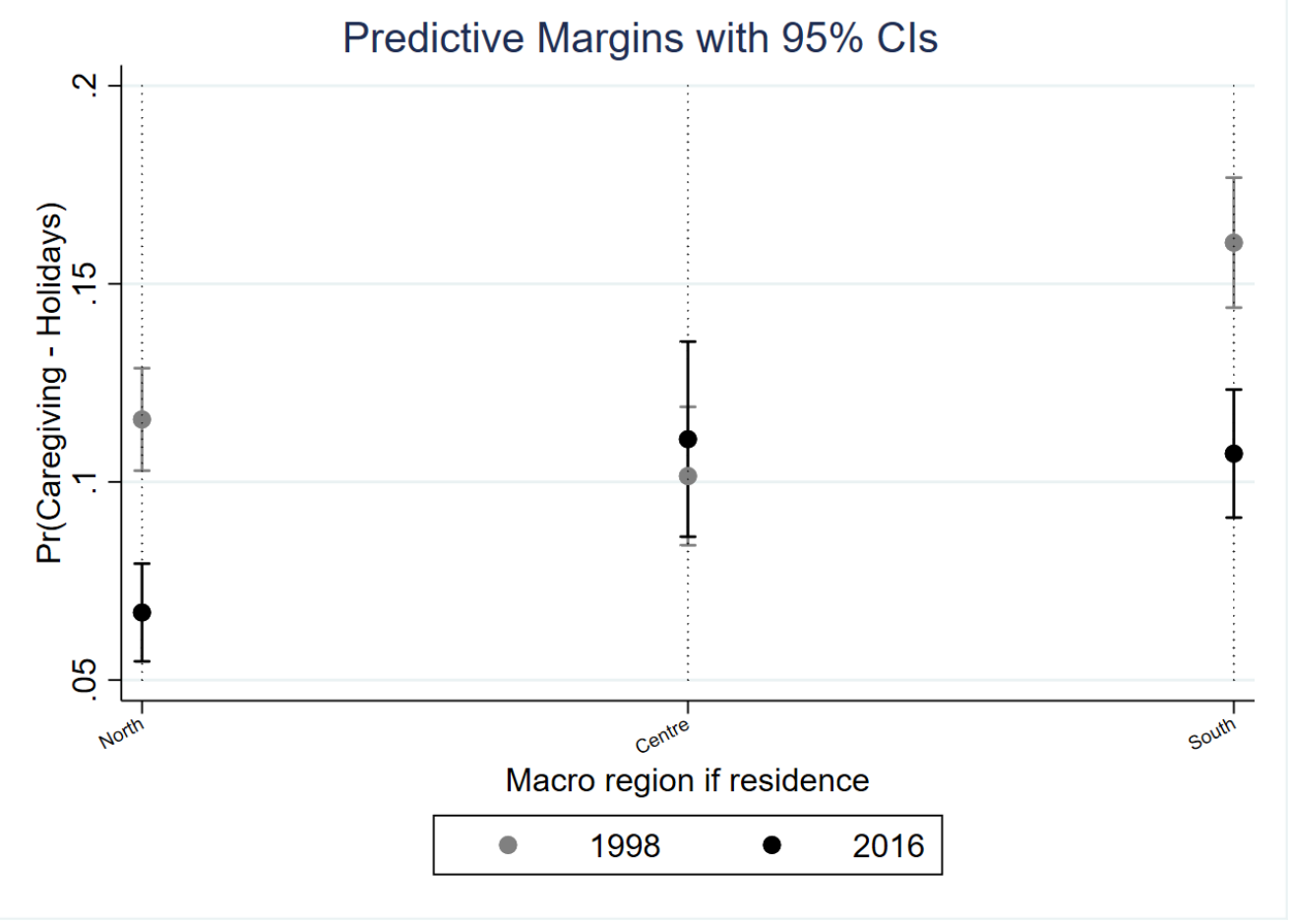

Panel c

Figure A.4 Predicted Probabilities Grandchild Care when parents work- Changes over time

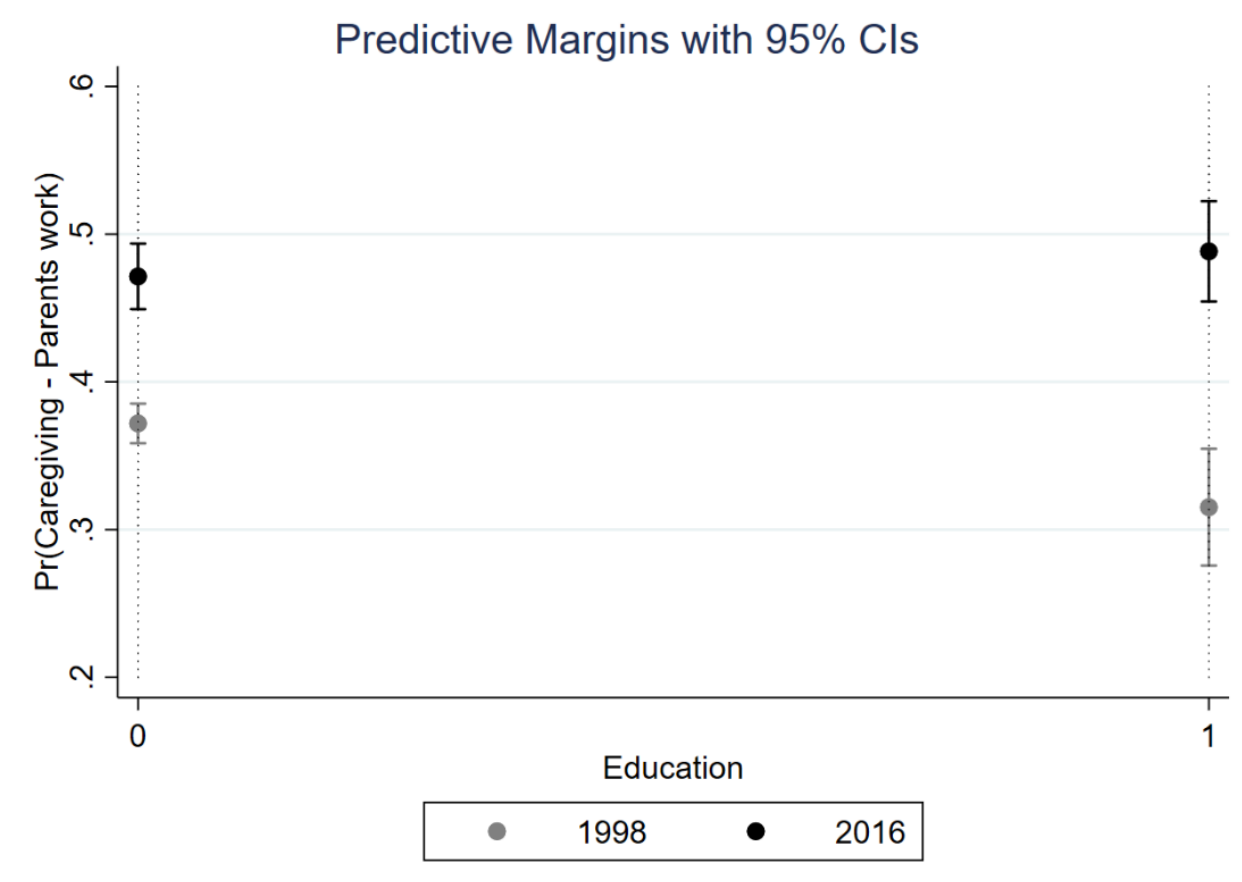

Panel a 


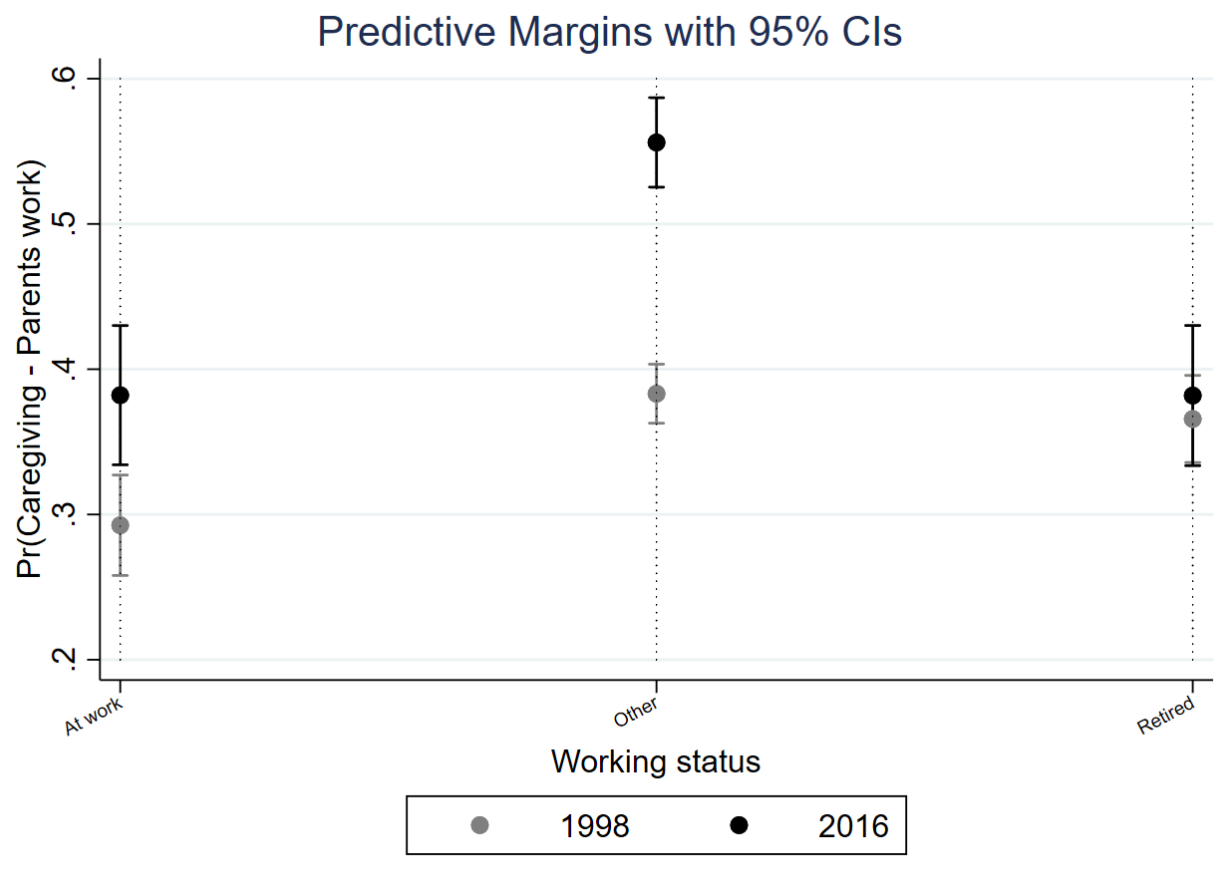

Panel b

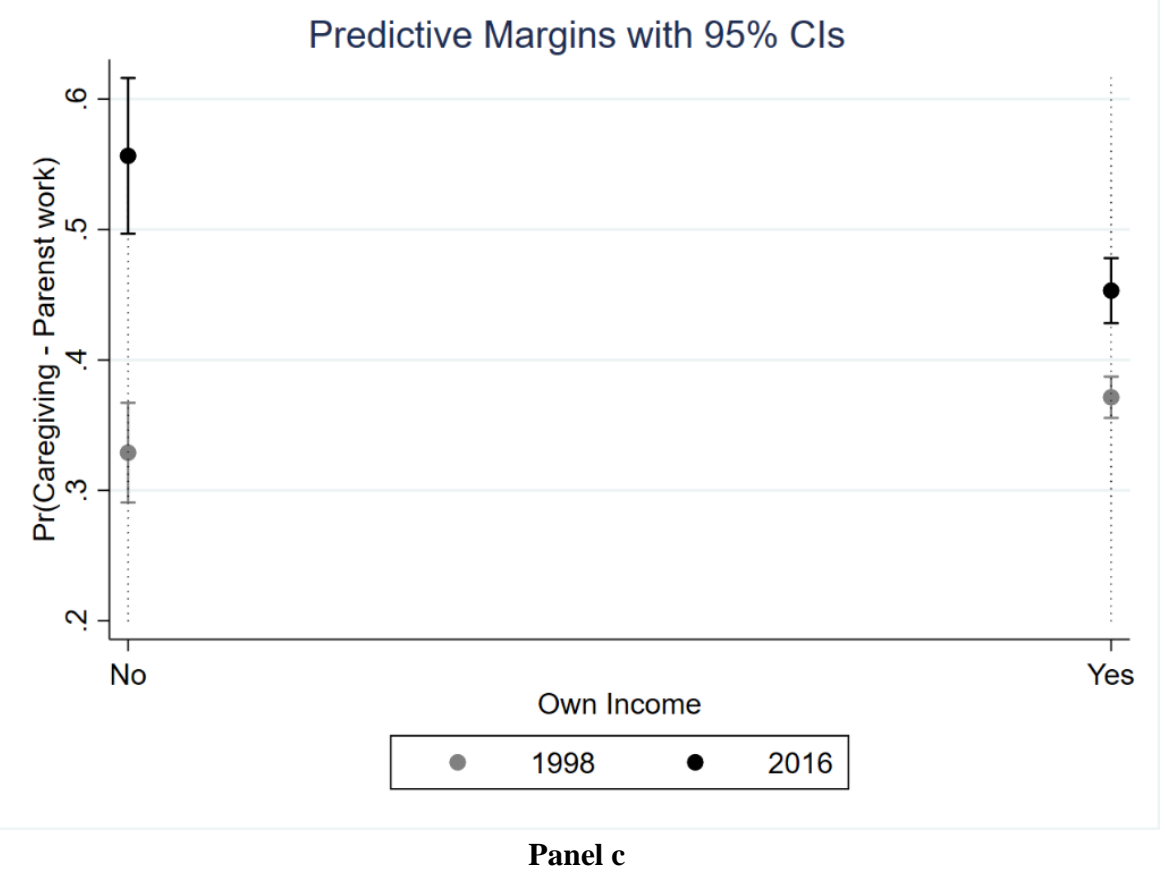




\section{References}

Aassve, A., Meroni, E., \& Pronzato, C. (2012). Grandparenting and childbearing in the extended family. European Journal of Population/Revue européenne de Démographie, 28(4), 499-518.

Albertini, M., \& Kohli, M. (2013). The generational contract in the family: An analysis of transfer regimes in Europe. European sociological review, 29(4), 828-840.

Albertini, M., \& Tosi, M. (2018). Grandparenting after parental divorce: The association between non-resident parent-child meetings and grandparenting in Italy. European Journal of Ageing, 15(3), 277-286. https://doi.org/10.1007/s10433-018-0478-z

Albuquerque PC. Grandparents in multigenerational households: the case of Portugal. European Journal of Ageing. 2011 Aug 4;8(3):189. doi: 10.1007/s10433-011-0196-2

Arpino, B., Pronzato, C. D., \& Tavares, L. P. (2014). The effect of grandparental support on mothers' labour market participation: An instrumental variable approach. European Journal of Population, 30(4), 369-390.

Arpino, B., Pasqualini, M. \& Bordone, V. Physically distant but socially close? Changes in nonphysical intergenerational contacts at the onset of the COVID-19 pandemic among older people in France, Italy and Spain. European Journal of Ageing 18, 185-194 (2021).

Bordone, V., Arpino, B., \& Aassve, A. (2017). Patterns of grandparental child care across Europe: the role of the policy context and working mothers' need. Ageing \& Society, 37(4), 845-873.

Cherlin, A., \& Furstenberg Jr, F. F. (1992). The new American grandparent. Harvard University Press.

Di Gessa, G., Glaser, K., \& Tinker, A. (2016a). The health impact of intensive and nonintensive grandchild care in Europe: New evidence from SHARE. Journals of Gerontology Series B: Psychological Sciences and Social Sciences, 71(5), 867-879.

Di Gessa, G., Glaser, K., Price, D., Ribe, E., \& Tinker, A. (2016b). What drives national differences in intensive grandparental childcare in Europe?. Journals of Gerontology Series B: Psychological Sciences and Social Sciences, 71(1), 141-153.

Di Gessa, G., Bordone, V., \& Arpino, B. (2020a). The role of fertility in the demography of grandparenthood: Evidence from Italy. Journal of Population Ageing, 1-19.

Di Gessa, G. , Zaninotto, P., \& Glaser, K. (2020b). Looking after grandchildren: gender differences in 'when,' 'what,'and 'why': Evidence from the English Longitudinal Study of Ageing. Demographic Research, 43(53), 1465-1482.

Fuller-Thomson, E., \& Minkler, M. (2001). American grandparents providing extensive child care to their grandchildren: Prevalence and profile. The Gerontologist, 41(2), 201-209.

Ganong, L. H., \& Coleman, M. (2006). Multiple segment factorial vignette designs. Journal of Marriage and Family, 68(2), 455-468

Geurts, T., Van Tilburg, T., Poortman, A. R., \& Dykstra, P. A. (2015). Child care by grandparents: changes between 1992 and 2006. Ageing \& Society, 35(6), 1318-1334.

Glaser, K., D. Price, G. Di Gessa, E. Ribe Montserrat, R. Stuchbury, and A. Tinker. 2013. Grandparenting in Europe: Family policy and grandparents' role in providing childcare. London: Grandparents Plus.

Glaser, K., Stuchbury, R., Price, D., Di Gessa, G., Ribe, E., \& Tinker, A. (2018). Trends in the prevalence of grandparents living with grandchild (ren) in selected European countries and the United States. European journal of ageing, 15(3), 237-250.

Grundy, E. (2000). Co-residence of mid-life children with their elderly parents in England and Wales: Changes between 1981 and 1991. Population Studies, 54(2), 193-206.

Grundy, E., \& Shelton, N. (2001). Contact between adult children and their parents in Great Britain 1986-99. Environment and planning A, 33(4), 685-697.

Grundy, E., \& Read, S. (2012). Social contacts and receipt of help among older people in England: are there benefits of having more children?. Journals of Gerontology Series B: Psychological Sciences and Social Sciences, 67(6), 742-754. 
Hank, K. (2007). Proximity and contacts between older parents and their children: A European comparison. Journal of Marriage and Family, 69(1), 157-173.

Hank, K., \& Buber, I. (2009). Grandparents caring for their grandchildren: Findings from the 2004 Survey of Health, Ageing, and Retirement in Europe. Journal of family Issues, 30(1), 53-73.

Hank, K., Cavrini, G., Di Gessa, G., \& Tomassini, C. (2018). What do we know about grandparents? Insights from current quantitative data and identification of future data needs. European Journal of Ageing, 15(3), 225-235.

Herlofson, K., \& Hagestad, G. O. (2012). Transformations in the role of grandparents across welfare states. Contemporary grandparenting: Changing family relationships in global contexts, $27-$ 50 .

Igel, C., \& Szydlik, M. (2011). Grandchild care and welfare state arrangements in Europe. Journal of European Social Policy, 21(3), 210-224.

Kalmijn, M. (2006). Educational Inequality and Family Relationships: Influences on Contact and Proximity. European Sociological Review, 22(1), 1-16.

Kalmijn, M., \& De Vries, J. (2009). Change and stability in parent-child contact in five Western countries. European Journal of Population/Revue europeenne de demographie, 25(3), 257 276.

Mancini, G. (2017). Women's labor force participation in Italy, 1861-2016 (No. 8). The Historical Household Budgets Project.

Mazurik, K., Knudson, S., \& Tanaka, Y. (2020). Stuck in the Nest? A Review of the Literature on Coresidence in Canada and the United States. Marriage \& Family Review, 56(6), 491-512.

McGarrigle, C.A., V. Timonen, and R. Layte. 2018. "Choice and Constraint in the Negotiation of the Grandparent Role: A Mixed-Methods Study." Gerontol Geriatr Med 4. $10.1177 / 2333721417750944$

Mueller, M.M. and Elder, G.H., Jr. (2003), Family Contingencies Across the Generations: Grandparent-Grandchild Relationships in Holistic Perspective. Journal of Marriage and Family, 65: 404-417. https://doi.org/10.1111/j.1741-3737.2003.00404.x

Murphy, M. (2011). Long-term effects of the demographic transition on family and kinship networks in Britain. PoPulation and develoPment review, 37, 55-80.

Oppelaar, J., \& Dykstra, P. A. (2004). Contacts between grandparents and grandchildren. Netherlands' Journal of Social Sciences, 40(2), 91-113.

Pilkauskas, N. V., \& Cross, C. (2018). Beyond the nuclear family: Trends in children living in shared households. Demography, 55(6), 2283-2297.

Popenoe, D. (1993). American family decline, 1960-1990: A review and appraisal. Journal of Marriage and the Family, 527-542.

Post, W., Van Poppel, F., Van Imhoff, E., \& Kruse, E. (1997). Reconstructing the extended kinnetwork in the Netherlands with genealogical data: Methods, problems, and results. Population Studies, 51(3), 263-278.

Ruggles, S. (2007). The decline of intergenerational coresidence in the United States, 1850 to 2000. American sociological review, 72(6), 964-989.

Saraceno, C. (2020). Politiche per le famiglie e disuguaglianze. Social Policies, 7(1), 103-124.

Silverstein, M. (1995). Stability and change in temporal distance between the elderly and their children. Demography, 32(1), 29-45.

Steinbach, A., Mahne, K., Klaus, D., \& Hank, K. (2020). Stability and change in intergenerational family relations across two decades: Findings from the German ageing survey, 1996-2014. The Journals of Gerontology: Series B, 75(4), 899-906.

Taylor, A. C., Robila, M., \& Lee, H. S. (2005). Distance, contact, and intergenerational relationships: Grandparents and adult grandchildren from an international perspective. Journal of Adult Development, 12(1), 33-41. 
Thornton, A., \& Young-DeMarco, L. (2001). Four decades of trends in attitudes toward family issues in the United States: The 1960s through the 1990s. J Journal of Marriage and Family, 63(4), 1009-1037.

Tomassini, C., Glaser, K., Wolf, DA., Broese van Groenou, M., Grundy, E. (2004a). Living arrangements among older people: an overview of trends in Europe and the USA, Population Trends, 115, 24-34

Tomassini, C., Kalogirou, S., Grundy, E., Fokkema, T., Martikainen, P., Van Groenou, M. B., \& Karisto, A. (2004b). Contacts between elderly parents and their children in four European countries: current patterns and future prospects. European Journal of Ageing, 1(1), 54-63.

Tomassini, C., \& Lamura, G. (2009). Population ageing in Italy and southern Europe. In International handbook of population aging (pp. 69-89). Springer, Dordrecht.

Treas, J., \& Gubernskaya, Z. (2012). Farewell to moms? Maternal contact for seven countries in 1986 and 2001. Journal of Marriage and Family, 74(2), 297-311.

Uhlenberg, P. \& Hamill, B. G. (1998). Frequency of grandparent contact with grandchild sets: Six factors that make a difference. The Gerontologist, 38, pp. 276-285.

Uhlenberg, P. (2005). Demography of aging. In Handbook of population (pp. 143-167). Springer, Boston, MA.

Van der Pas, S., Van Tilburg, T., \& Knipscheer, K. (2007). Changes in contact and support within intergenerational relationships in the Netherlands: A cohort and time-sequential perspective. Advances in Life Course Research, 12, 243-274.

Zamberletti, J., G. Cavrini, \& C. Tomassini. (2018) Grandparents providing childcare in Italy. European Journal of Ageing, Vol. 15, 3:265-275.

Westphal, S.K., Poortman, A.-R. and Van der Lippe, T. (2015), What About the Grandparents? Children's Postdivorce Residence Arrangements and Contact With Grandparents. Family Relations, 77: 424-440. https://doi.org/10.1111//omf.12173

Wolf, D. A., \& Longino Jr, C. F. (2005). Our "increasingly mobile society"? The curious persistence of a false belief. The Gerontologist, 45(1), 5-11. 